\title{
PERANCANGAN APLIKASI CLIENT UNTUK JARINGAN VOIP (VOICE OVER INTERNET PROTOCOL) BERBASIS ANDROID
}

\author{
Yasdinul Huda ${ }^{1}$ \\ Muhammad Adri ${ }^{2}$ \\ Yoharmen Arnov ${ }^{3}$
}

\begin{abstract}
Communication is a necessity in the operation of an agency or company. Inexpensive communications using VOIP will provide for the expense of the agency or company. In communication required a reliable network system with the concept of client for the user of a system and server as a network manager used by client. VOIP requires a server using a PC with Ubuntu Linux 12.04 LTE or Linphone as a VOIP (Voice Over Internet Protocol) server and an asterisk for managing voice traffic. android software on the client side to be the interface in communicating with other clients designed using Android Studio with android smartphone at least 4.4 .2 (kitkat). And requires internet connection via WIFI_UNP as the transmission medium (link) between server and client. WIFI_UNP is an internet medium used by students, lecturers, staff and employees of State University of Padang to support the learning process and add insight about the latest technology or science. While tethering hotspot is an internet media that comes from internet connection from Smartphone which is shared or distributed to other users for internet. This VOIP Client application provides two main functions: Calling and Chat. On Calling will be granted permissions to make voice calls by entering the client username to be contacted or VOIP number that has been registered. While Chat is a feature to perform realtime (in accordance with the actual time) text chat .
\end{abstract}

Keywords : Client Application, Server, VOIP, Ubuntu Linux, Android.

\footnotetext{
${ }^{1}$ Dosen Universitas Negeri Padang

2. Dosen Universitas Negeri Padang

3. Jurusan Teknik Elektronika UNP
} 


\section{INTI SAR I}

Komunikasi adalah suatu keharusan dalam operasi suatu agen atau perusahaan. Komunikasi murah menggunakan VOIP akan menyediakan biaya agensi atau perusahaan. Dalam komunikasi diperlukan suatu sistem jaringan yang handal dengan konsep client untuk pengguna suatu sistem dan server sebagai pengelola jaringan yang digunakan oleh klien. VOIP memerlukan server menggunakan PC dengan Ubuntu Linux 12.04 LTE atau Linphone sebagai server VOIP (Voice Over Internet Protocol) dan tanda bintang untuk mengatur lalu lintas suara. perangkat lunak android di sisi klien untuk menjadi antarmuka dalam berkomunikasi dengan klien lain yang dirancang menggunakan Android Studio dengan smartphone android setidaknya 4.4.2 (kitkat). Dan membutuhkan koneksi internet melalui WIFI_UNP sebagai media transmisi (tautan) antara server dan klien. WIFI_UNP adalah media internet yang digunakan oleh mahasiswa, dosen, staf dan karyawan Universitas Negeri Padang untuk mendukung proses pembelajaran dan menambah wawasan tentang teknologi atau sains terbaru. Sedangkan tethering hotspot adalah media internet yang berasal dari koneksi internet dari Smartphone yang dibagikan atau didistribusikan ke pengguna lain untuk internet. Aplikasi VOIP Client ini menyediakan dua fungsi utama: Memanggil dan Mengobrol. On Calling akan diberikan izin untuk melakukan panggilan suara dengan memasukkan nama pengguna klien untuk dihubungi atau nomor VOIP yang telah didaftarkan. Sedangkan Obrolan adalah fitur untuk melakukan obrolan teks secara realtime (sesuai waktu yang sebenarnya).

Kata Kunci : Aplikasi Klien,Server, VOIP, Ubuntu Linux, Android 


\section{PENDAHULUAN}

Dewasa ini jaringan komunikasi telah menjadi suatu kebutuhan yang cukup penting bagi manusia. Hampir di setiap perusahaan memerlukan alat komunikasi yang ditujukan untuk mempermudah kegiatan operasional sehari-hari perusahaan. Jaringan komunikasi ini merupakan infrastruktur penting yang harus diperhatikan dan dikelola kinerjanya dengan baik.

Agar dapat bekerja dengan baik, maka jaringan tersebut harus dikelola dengan benar, baik dari segi performa, topologi, maupun keamanannya. Adanya gangguan kecil dan kurangnya stabilitas pada jaringan komunikasi suatu perusahaan dapat menyebabkan tidak lancarnya arus komunikasi perusahaan sehingga dapat menyebabkan kerugian pada perusaahaan tersebut.

Manfaat berkomunikasi dengan voice menggunakan jaringan data menurut Winarno Sugeng (2007 : 5), antara lain "Efesiensi alokasi bandwith, kemampuan untuk menggunakan metode kompresi suara, menekan biaya penggunaan, kemampuan menggunakan single interface, meningkatkan keandalan (reliability) jaringan komputer, dan termasuk menekan biaya operasional komunikasi hingga mendekati gratis (Rp. 0,-) jika menggunakan LAN"

Hal ini menjadikan persaingan pada provider untuk menekan harga jual paket 4G untuk dapat dinikmati pelanggannya, maka solusi komunikasi dengan via VOIP akan sangat murah untuk digunakan dibandingkan dengan menelpon pada jaringan suara konvensional dengan pulsa dari kartu provider. VOIP tidak dikenakan roaming untuk menelpon ke beda negara karena hanya menggunakan paket data internet yang dibeli, kompresi suara pada VOIP sangat kecil sehingga dapat menekan tingginya quota yang dipakai dalam komunikasi suara karena ada empat unsur yang membentuk jaringan VOIP menurut Onno W. Purbo dari buku
VOIP Cikal Bakal "Telkom Rakyat", yaitu: User Agent, Proxy, Protocol dan CODEX (Coder-Decoder).

Jaringan komputer merupakan salah satu cara dari penerapan teknologi informasi. Karena pentingnya jaringan komputer, dewasa ini hampir seluruh perusahaan menggunakan media jaringan komputer dalam komunikasi datanya. Karena melalui jaringan komputer diijinkan pengaksesan atau komunikasi data secara bersama. Untuk memungkinkan komunikasi data diantara komputer dalam sebuah jaringan, diperlukan sebuah perangkat pengontrol jaringan seperti server. Pengaturan dan pengontrolan yang dilakukan server dalam jaringan meliputi kontrol hak akses terhadap suatu bentuk sumber informasi dan kontrol komunikasi data. Karena itu VOIP membutuhkan sebuah server menggunakan PC dengan Linux Ubuntu 12.04 LTE atau Linphone sebagai server VOIP (Voice Over Internet Protocol) dan asterisk untuk mengelola lalulintas suara. software android di sisi client untuk menjadi interface dalam berkomunikasi dengan client lain yang dirancang menggunakan Android Studio dengan smartphone android minimal 4.4.2 (kitkat). Dan membutuhkan koneksi internet melalui WIFI_UNP sebagai media transmisi (penghubung) antara server dan client. WIFI_UNP merupakan media internet yang digunakan mahasiswa, dosen, staff serta karyawan Universitas Negeri Padang untuk menunjang proses pembelajaran dan menambah wawasan tentang teknologi atau ilmu pengetahuan terbaru. Sedangkan tethering hotspot merupakan media internet yang berasal dari sambungan internet dari Smartphone yang disharing atau dibagikan kepada pengguna lain untuk internet.

Tujuan dari penelitian ini adalah merancang sebuah aplikasi client untuk komunikasi melalui panggilan suara dan chat. Sistem yang 
dikembangkan mengikuti arsitektur client-server, dengan client terdiri dari aplikasi berbasis android. Aplikasi mobile dibangun menggunakan editor Android Studio v.3.1.0.

\section{PENDEKATAN \\ MASALAH \\ Perancangan}

Sistem yang akan dibangun memakai metode client-server dalam arsitekturnya, arsitektur dalam pada sistem ini terdiri 3 komponen utama yaitu, android application, server application, dan database server. Android client application merupakan aplikasi yang digunakan oleh user sebagai alat komunikasi VOIP. Pada android client application terdapat fitur untuk memanggil dan chat dengan user lain menggunakan DNS (Domain Name Server) yang telah terdaftar pada server.

Server VOIP dibangun menggunakan Sistem Operasi Linux Ubuntu 12.04. Dan software Asterisk untuk menggelola user VOIP yang akan berkomunikasi. Database server menggunakan SQL Lite yang berfungsi sebagai media penampung data dari keseluruhan data yang diolah di web admin.

1) Linux Ubuntu 12.04LTS

Canonical, perusahan dibalik distro Linux popular Ubuntu telah meluncurkan edisi LTS (Long Term Support) versi 12.04 dengan nama kode "Precise Pangolin" tepat waktu sebagaimana dijadwalkan sebelumnya, pada tanggal 26 April 2012 lalu. Edisi khusus LTS yang diluncurkan dua tahun sekali menjanjikan dukungan perbaikan selama 5 tahun baik untuk server maupun desktop. Pada versi-versi LTS sebelumnya (10.04 dan 8.04), hanya dukungan 5 tahun hanya berlaku untuk server, sedangkan desktop didukung selama 3 tahun.
2) Asterisk

Asterisk adalah implementasi perangkat lunak dari "telephone private branch exchange (PBX)", diciptakan pada tahun 1999 oleh Mark Spencer dari Digium. Seperti PBX lainnya, dimungkinkan memasang pesawat telepon dan melakukan panggilan ke satu dengan lainnya, termasuk tersambung ke layanan telepon pribadi dan publik, termasuk layanan jaringan telepon umum (PSTN) dan Voice Over Internet Protocol (VOIP). Nama Asterisk berasal dari * (tanda bintang). Asterisk dirilis menganut model lisensi ganda, menggunakan GNU/GPL sebagai lisensi perangkat lunak bebas dan lisensi perangkat lunak berpemilik untuk mengizinkan pemegang lisensi untuk mendistribusikan komponen sistem proprietari yang tidak perlu dipublikasikan.

3) Android Studio

Android Studio menurut Alfa Satyaputra dan Eva Maulina Aritonang (2016 : 63) adalah "IDE resmi untuk membangun aplikasi Android berdasarkan IntelliJ IDEA". IntelliJ IDEA sendiri adalah Java Integrated Development Environment (IDE) yang dikembangkan oleh JetBrains, untuk mengembangkan perangkat lunak (software) komputer. IntelliJ IDEA berfungsi dalam membantu Anda dalam dunia per-coding-an baik dari segi navigasi, penyokong produktivitas, hingga code editor yang cerdas. Android Studio dibangun dengan tujuan mempercepat proses pembangunan maupun pengembangan aplikasi Android yang berkualitas tinggi untuk setiap device Android. Google 
mengakuisisi Android Inc pada bulan Agustus 2005 sebagai anak perusahaan yang sepenuhnya dimiliki dari tujuan utama Google Inc. Google adalah untuk menyediakan platform terbuka penuh, yang didukung oleh teknologi Google, baik untuk pengguna dan pengembang aplikasi. Pada bulan November 2007, Open Handset Alliance didirikan sebagai konsorsium untuk mengembangkan standar terbuka untuk perangkat mobile. Open Handset Alliance memulai perjalanannya dengan mengumumkan platform Android. Dalam waktu kurang dari satu tahun, anggota baru mulai bergabung konsorsium ini (Nazruddin Safaat, 2015).

4) SQLite

Aplikasi Android umumnya perlu menyimpan dan mengolah data-data yang beragam jenisnya. Contohnya, sebuah game RPG (Role Playing Game) yang menyimpan data-data karakter, musuh, peta dunia, inventori, magic, items dan sebagainya. Atau aplikasi yang menyimpan data diri berupa data nama, alamat, nomor telepon, $e$ mail, dan sebagainya. Untuk menyimpan data-data tersebut secara aman, rapi dan terstuktur, Anda dapat menggunakan fitur database yang sudah tersedia dalam Android, yaitu SQLite.

5) Linphone WebServer

Linphone adalah server VOIP yang memungkinkan pengguna untuk memanggil teman-teman mereka dari mana saja di dunia tanpa membayar lebih bahwa biaya sebenarnya dari koneksi internet mereka.

Server ini memungkinkan pengguna untuk melakukan konfigurasi panggilan suara, memulai konferensi video, serta teks teman-teman mereka menggunakan (instant messaging) protokol IM. Untuk sistem telepon internet, aplikasi yang menggunakan standar terbuka dan protokol SIP terkenal.

Untuk

memanggil

seseorang, pengguna harus menyediakan SIP (Session Initiation Protocol) URL yang terlihat seperti alamat email. Anda harus diketahui SIP URL sebelum memulai panggilan telepon, tetapi Anda juga dapat menggunakan alamat IP standar.

Dalam istilah yang lebih teknis, aplikasi dilengkapi dengan SIP UA (User Agent) yang sesuai dengan RFC 3261, mendukung protokol IPv6, mendukung SIP / UDP, SIP / TCP dan protokol SIP / TLS, serta digest otentikasi. Mendukung beberapa panggilan dan SIP proxy. Selain itu, aplikasi ini mendukung beberapa panggilan pada waktu yang sama dan beberapa proxy SIP (proxy outbound, registrar, dan lain-lain). Hal ini juga termasuk dukungan pemberitahuan pengiriman untuk komponen instant messaging. Fitur manajemen panggilan standar disediakan, termasuk berpegang pada dengan musik, mentransfer panggilan atau melanjutkan DTMF (nada telepon) dukungan juga disertakan, berdasarkan RFC 2833 atau spesifikasi SIP INFO. Ini adalah sebuah server yang ultra portable, yang telah berhasil diuji dengan Linux, Windows, MacOS $X$, Android, iOS, BlackBerry dan WebOS sistem operasi. 64-bit, 32-bit dan ARM arsitektur yang didukung. Dapat disimpulkan bahwa, Linphone terbukti menjadi alternatif yang sangat baik untuk aplikasi 
telepon Internet (VOIP). Hal ini secara aktif dikembangkan, berjalan pada berbagai platform dan menyediakan koleksi plugin codec.

Use Case pada diagram Arsitektur Client-Server dijelaskan pada Gambar 1.

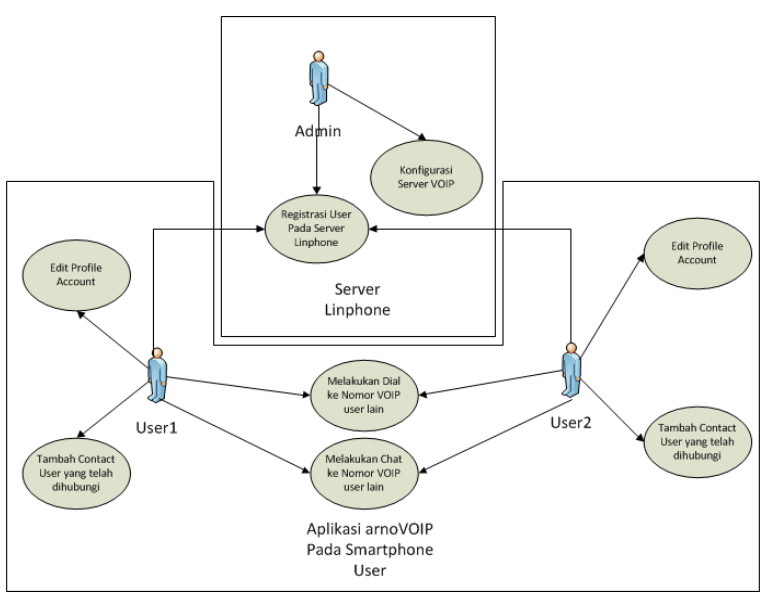

Gambar 1. Use Case Diagram Arsitektur Client-Server

Gambar 1 menggambarkan bahwa server Linphone berbasis web digunakan untuk registrasi user dan konfigurasi server VOIP dan aktor yang mengelola server Linphone adalah Admin. Pada Aplikasi VOIP yang diberi nama "arnoVoip" ini digunakan oleh 2 user yang berbeda untuk berkomunikasi suara atau pesan teks. Setiap user dapat melakukan edit profile account dan tambah contact user yang telah dihubungi.

$$
\text { Class }
$$

diagram menggambarkan keadaan sistem (attribut), dan memberikan pelayanan untuk menyelesaikan keadaan tersebut (metoda). Pada gambar class diagram dari sistem Aplikasi client VOIP. Untuk Class Diagram database dari aplikasi dijelaskan pada Gambar 2.

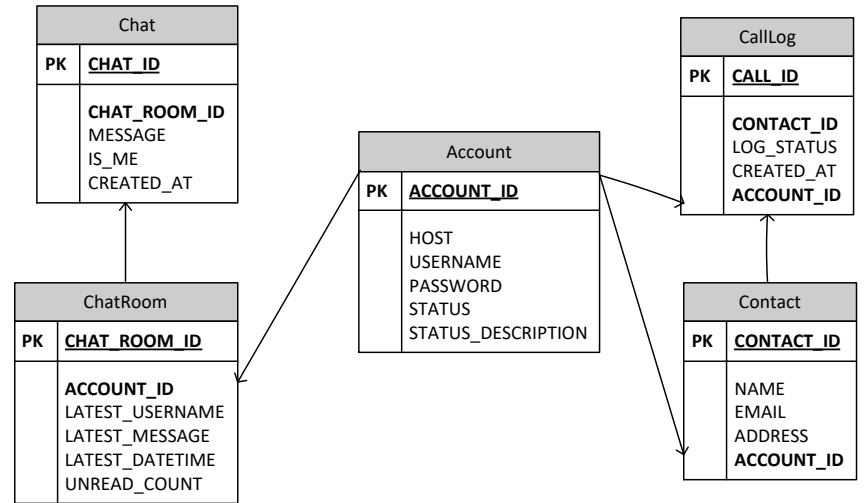

Gambar 2. Class Diagram

Gambar 2 menunjukkan bahwa tabel yang digunakan pada database aplikasi sebanyak 5 tabel yaitu :

a. Chat, untuk informasi dari chat yang masuk dari user lain.

b. ChatRoom, untuk data personal chat dengan user lain.

c. Account, untuk data aktivasi akun dari aplikasi

d. CallLog, untuk informasi dari semua panggilan

e. Contacts, untuk data kontak yang akan dihubungi.

Perancangan antarmuka dibutuhkan untuk mewakili keadaan sebenarnya dari aplikasi yang kan dibangun. Berikut tampilan antar muka aplikasi VOIP yang digunakan pada sisi client Pada Gambar 3.

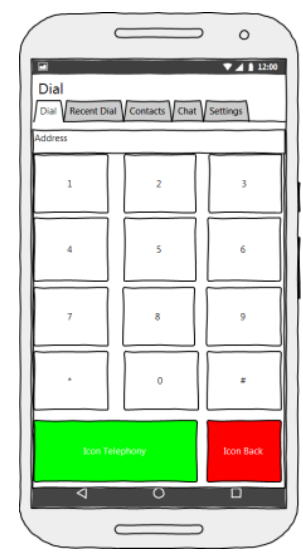

Gambar 3. Disain Tampilan Menu Dial 
Disain tampilan menu Dial pada Gambar 3 merupakan tampilan awal aplikasi yang dilihat oleh user. User menekan tombol nomor VOIP atau memasukkan username yang akan dihubungi kemudian user menekan tombol hijau untuk menelpon. Tombol merah untuk menghapus nomor atau username yang telah dimasukkan kedalam textbox address. Untuk Menu Recent Dial user cukup menekan tab menu Recent Dial seperti Gambar 4.

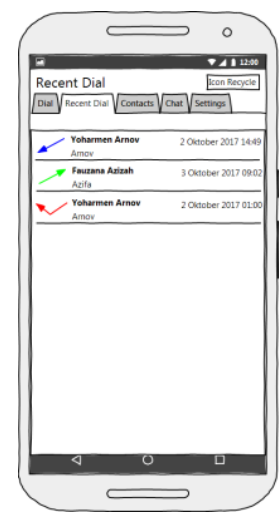

Gambar 4. Disain Tampilan Menu Recent Dial

Gambar 4 merupakan Menu Recent Dial adalah menu yang akan menampilkan seluruh panggilan yang telah masuk, keluar atau tidak terjawab. Menu Contacts dapat dijelaskan pada Gambar 5.

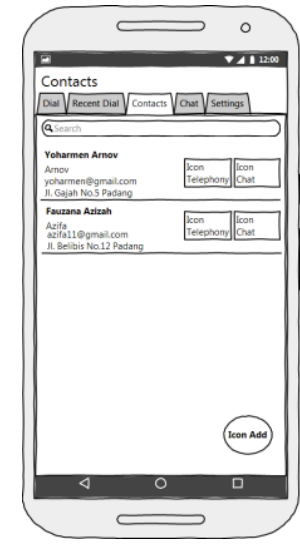

Gambar 5. Disain Tampilan Menu Contacts

Setelah memilih menu tab Contacts maka akan muncul list kontak yang telah disimpan pada database aplikasi seperti Gambar 5. Pada halaman ini user juga dapat langsung melakukan panggilan suara atau chat dengan menekan icon yang ada di sebelah kanan nama kontak tersebut. Untuk menu Chat dapat dijelaskan pada Gambar 6.

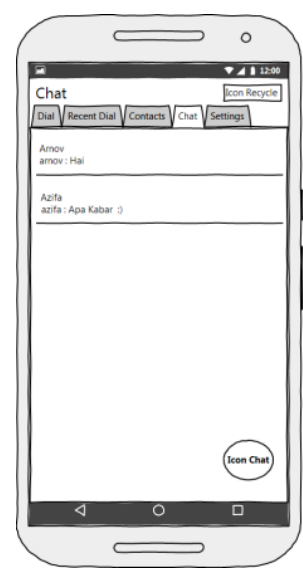

Gambar 6. Disain Tampilan Menu Chat

Halaman chat pada Gambar 6 digunakan user untuk melakukan obrolan teks dengan user lain. Untuk memulai chat maka user harus menekan tombol new chat yang ada pada pojok kanan bawah dari aplikasi ini. Untuk tampilan menu Settings dilihat pada Gambar 7. 


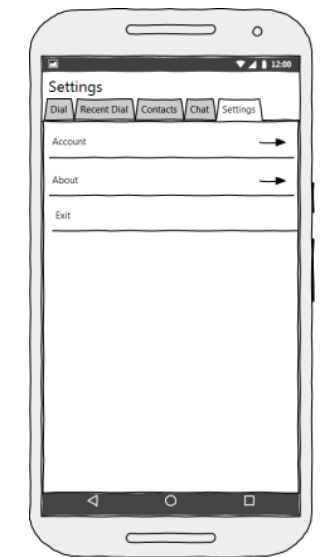

Gambar 7. Disain Tampilan Menu Settings

Menu Settings pada Gambar 7 terdapat 3 pilihan sub menu yaitu: Account, About, dan Exit. Account digunakan untuk mengaktifkan account yang akan digunakan pada aplikasi ini. About adalah informasi mengenai aplikasi ini. Untuk mengetahui user sedang melakukan panggilan VOIP maka akan muncul halaman Calling seperti Gambar 8.

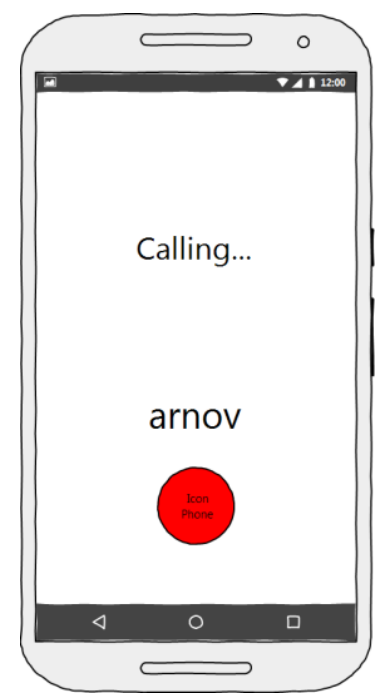

Gambar 8. Disain Tampilan Calling

Halaman Calling pada Gambar 8 tampil ketika user melakukan panggilan VOIP, untuk mengakhiri panggilan user harus menekan tombol merah.
Tampilan Personal Chat dijelaskan pada Gambar 9.

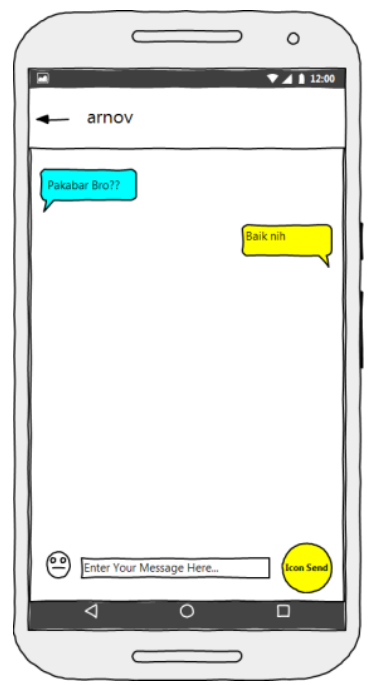

Gambar 9. Disain Tampilan Chat

Halaman chat pada Gambart 9 tampil ketika user sudah memasukkan username yang akan di-chat. Halaman ini adalah chat yang real time. Chat berwarna kuning adalah chat dari user pengguna aplikasi sedangkan chat berwarna biru adalah chat lawan bicaranya.

\section{HASIL DAN PEMBAHASAN Hasil Rancangan}

Hasil rancangan ini membahas tampilan antarmuka aplikasi client untuk jaringan VOIP. Terdapat beberapa hasil rancangan antarmuka dalam aplikasi untuk melakukan panggilan suara dan chat, berikut pembahasan tampilan antarmuka tersebut. Splash screen adalah tampilan pertama ketika aplikasi dibuka. Berikut tampilan splash screen pada Gambar 10 


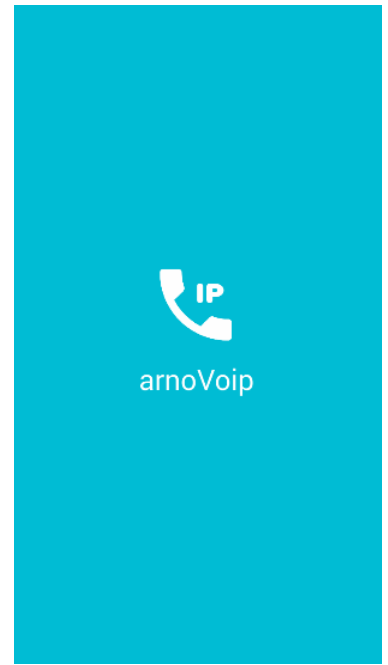

Gambar 10. Tampilan Splash Screen

Halaman menu utama tampil setelah tampilan splash screen selesai seperti Gambar 10. Pada menu utama menampilkan beberapa menu yaitu Dial, Recent Dial, Contact, Chat dan Setting yang akan dijelaskan pada poin berikutnya. Berikut tampilan menu utama pada aplikasi client untuk jaringan VOIP. Tampilan menu utama dijelaskan pada Gambar 11.

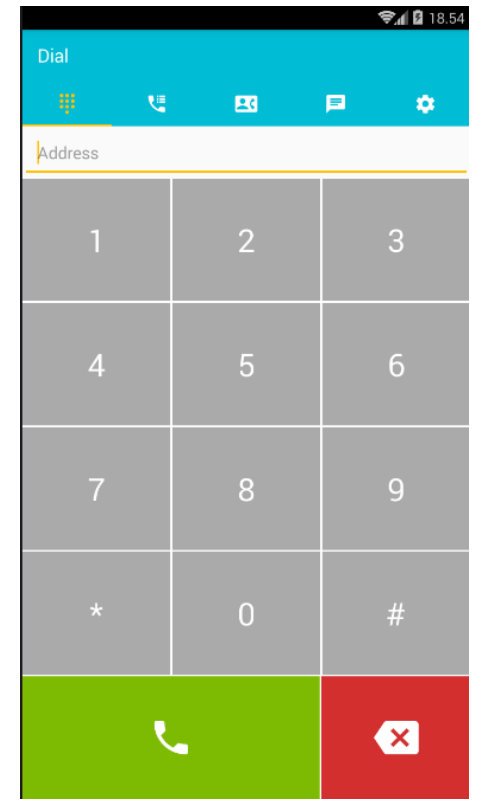

\section{Gambar 11.Tampilan MenuUtama}

$\begin{array}{lcc}\text { Gambar } 11 & \text { merupakan } \\ \text { tampilan menu utama yang ada } \\ \text { diaplikasi setelah }\end{array}$

berjalan. Menu utama berfungsi untuk memanggil nomor VOIP atau id account user yang akan dihubungi.

Halaman Recent Dial berisikan tentang informasi seluruh panggilan yang masuk, keluar dan tidak terjawab. Halamam menu recent dial dapat dilihat pada Gambar 12 berikut ini :

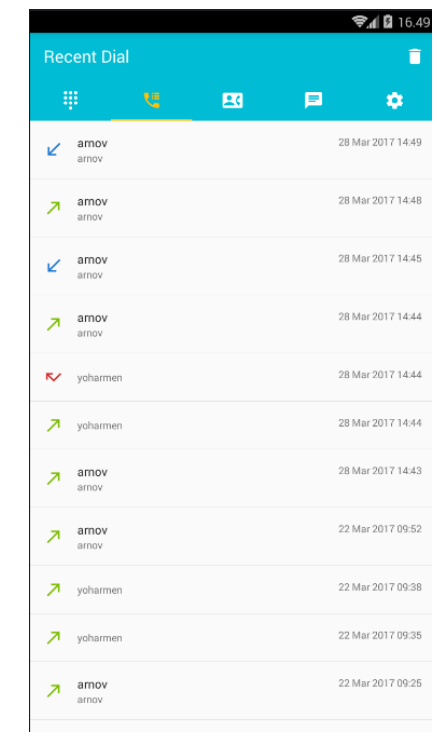

Gambar 12. Tampilan Recent Dial

Halaman Recent Dial pada Gambar 12 untuk melihat informasi seluruh data panggilan VOIP.

Halaman Contact berisikan informasi dari kontak yang telah disimpan pada aplikasi ini. Halaman menu contact dapat dilihat pada Gambar 13 berikut ini : 


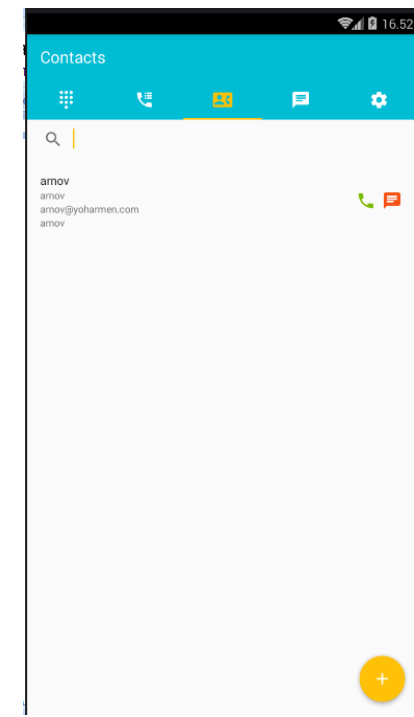

Gambar 13.Tampilan Contact

Halaman menu chat akan menampilkan informasi dari chat yang telah dilakukan oleh user pada aplikasi ini. Halaman chat dapat dilihat pada Gambar 14 dibawah ini :

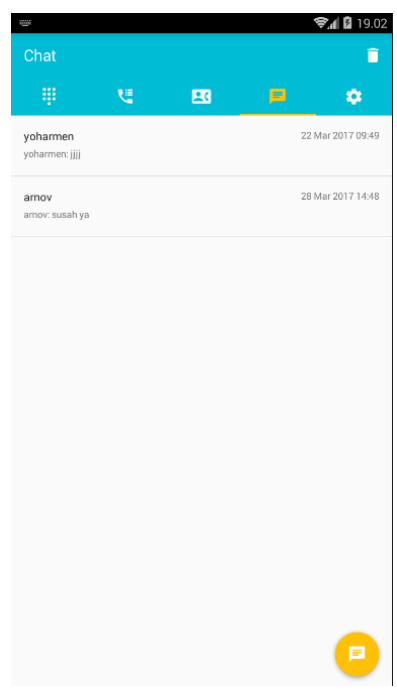

\section{Gambar 14.Tampilan Chat}

Antarmuka dari halaman chat personal merupakan halaman yang akan muncul ketika user telah memasukkan username kontak yang dituju untuk chat dapat dilihat pada Gambar 15.

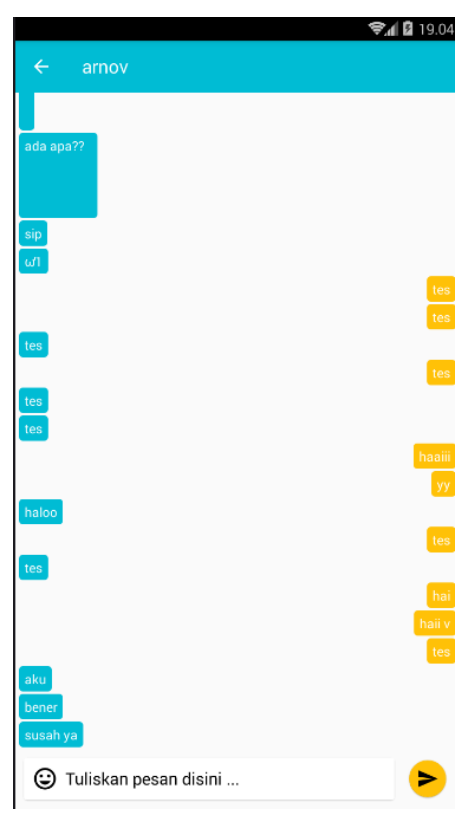

Gambar 15. Halaman Chat Personal

Antarmuka halaman untuk melakukan panggilan VOIP akan muncul setelah user memasukkan nomor VOIP atau username yang akan dihubungi pada menu dial dijelaskan pada Gambar 16.

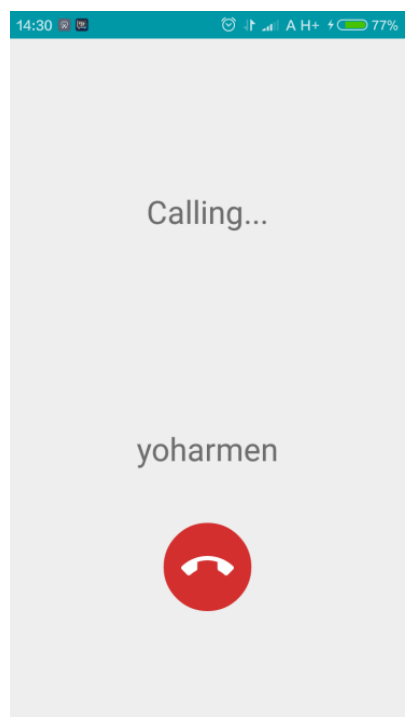

Gambar 16.Tampilan panggilan VOIP

Jika user akan mengakhiri panggilan VOIP, maka user cukup menekan tombol icon telefon yang berwarna merah pada Gambar 17. Maka akan muncul halaman Call End seperti dibawah ini. 


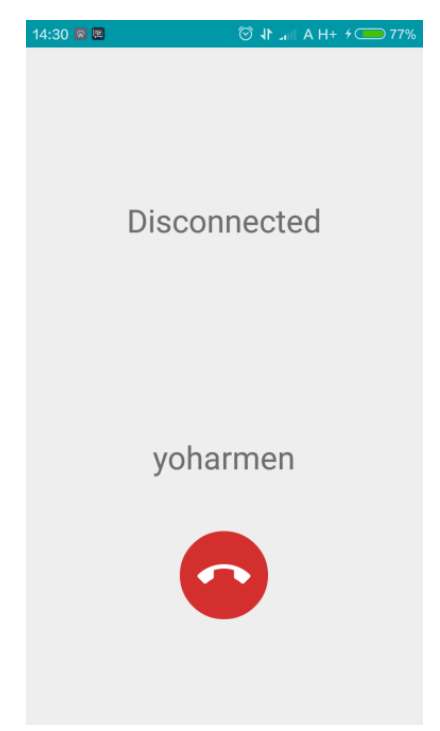

Gambar 17.Tampilan Call End

Halaman yang muncul pada penerima telefon yang dipanggil akan muncul halaman panggilan masuk seperti Gambar 18 dibawah. Untuk menerima telefon maka user harus menekan tombol hijau dan untuk menolak maka user harus menekan tombol merah.

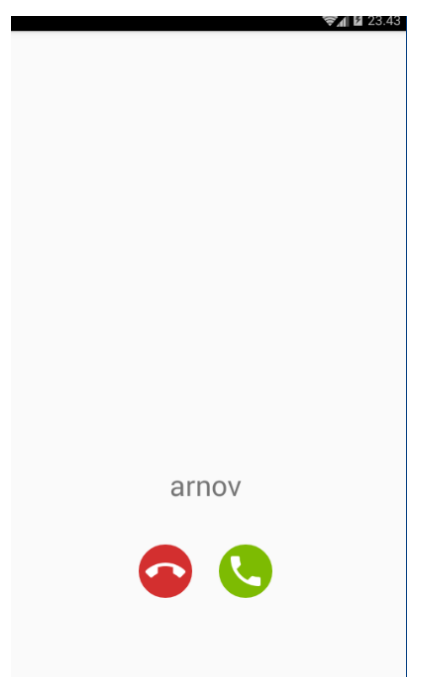

Gambar 18.Tampilan panggilan masuk

Halaman webserver dari
Linphone yang berfungsi untuk
mengelola user yang akan
menggunakan komunikasi VOIP.
Halaman Registrasi User dijelaskan
pada Gambar 19 berikut:

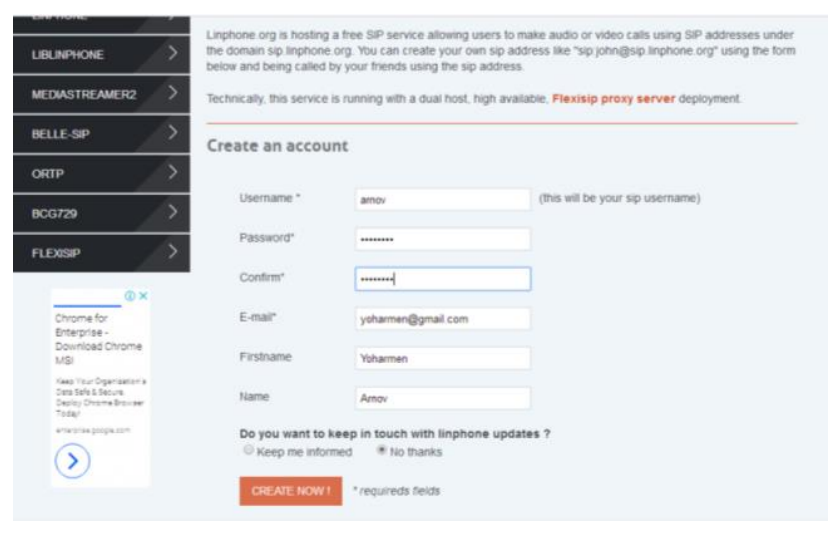

Gambar 19. Halaman Registrasi User

Antarmuka halaman activation account adalah halaman antarmuka yang muncul pada email user yang telah melakukan registrasi pada Linphone webserver digambarkan seperti Gambar 20 berikut :

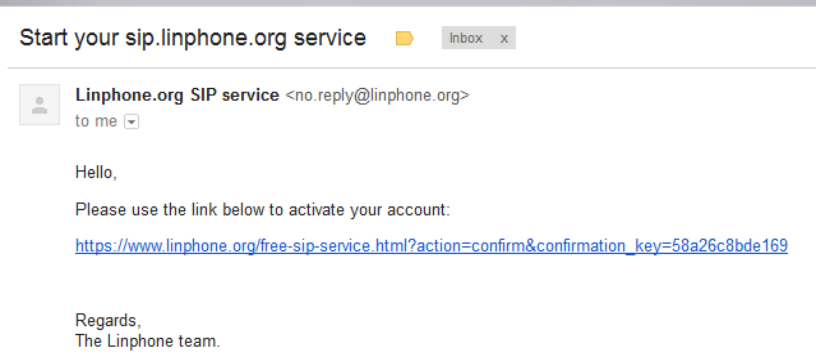

\section{Gambar 20. Tampilan Halaman Activation Account}

Setelah user menekan link aktivasi pada email-nya maka browser akan mengarahkan ke halaman informasi detail aktivasi pada Linphone Webserver. Tampilan account yang sudah aktif dapat dilihat pada Gambar 21.

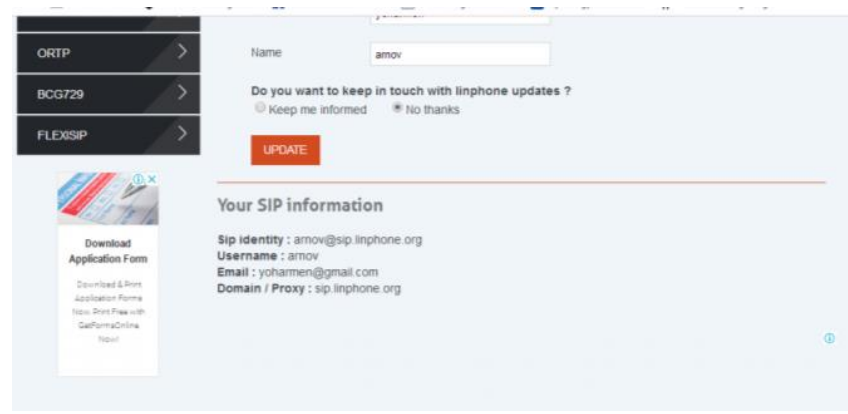

Gambar 21.Tampilan account yang sudah aktif 
Tampilan Server Ubuntu 12.04 yang akan mengelola konfigurasi VOIP pada aplikasi. Tampilan login muncul setelah proses booting server selesai seperti Gambar 22.

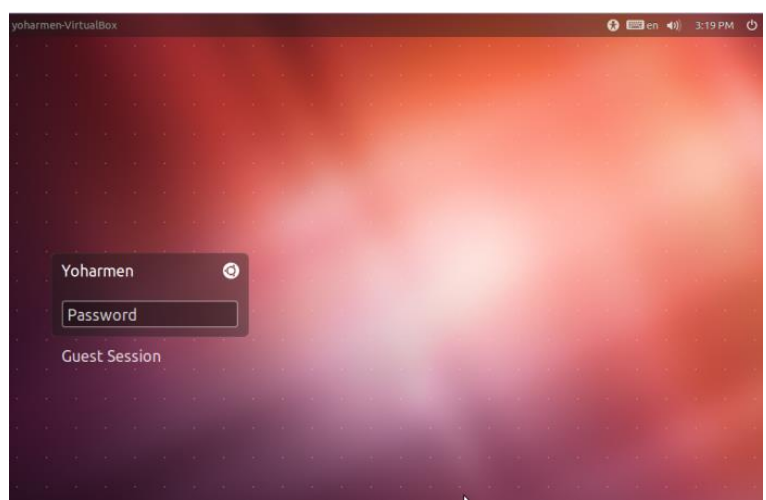

Gambar 22.Tampilan login Ubuntu 12.04

Tampilan desktop dari Ubuntu 12.04 yang berisikan aplikasi dan tool dari sistem operasi Linux tersebut pada Gambar 23 berikut:

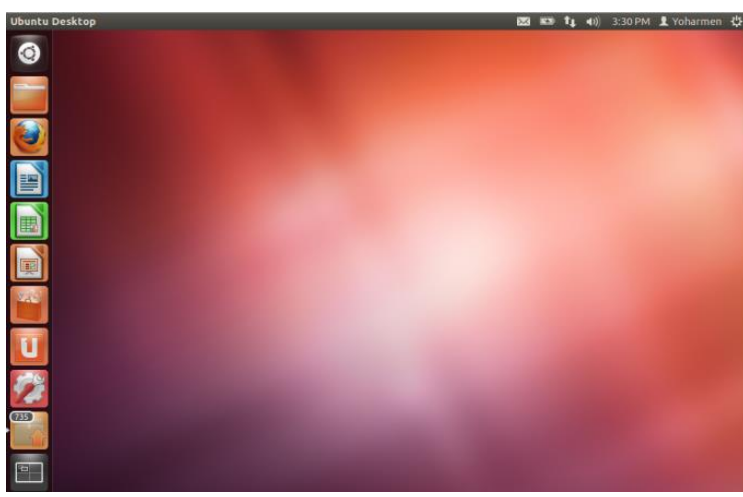

Gambar 23.Tampilan Desktop Ubuntu 12.04

Tampilan instalasi asterisk dengan mengetikkan perintah apk-get install asterisk pada terminal linux seperti Gambar 24 dibawah ini.

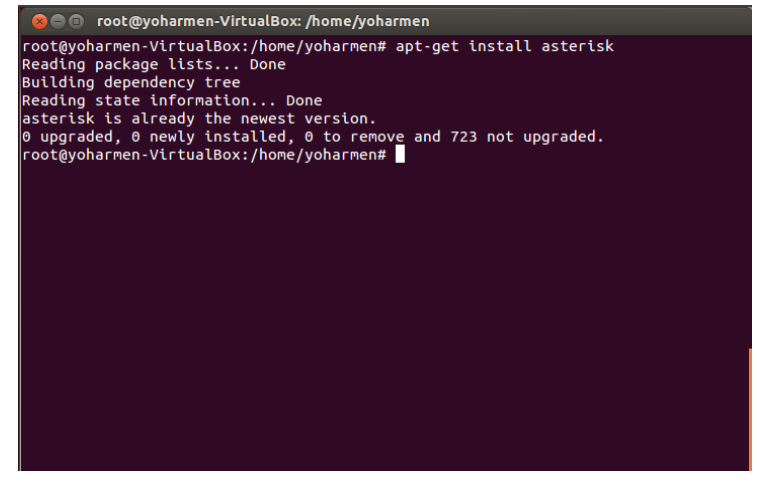

Gambar 24.Tampilan instalasi asterisk

Tampilan konfigurasi sip.conf untuk detail dari user VOIP dapat dijelaskan pada Gambar 25.

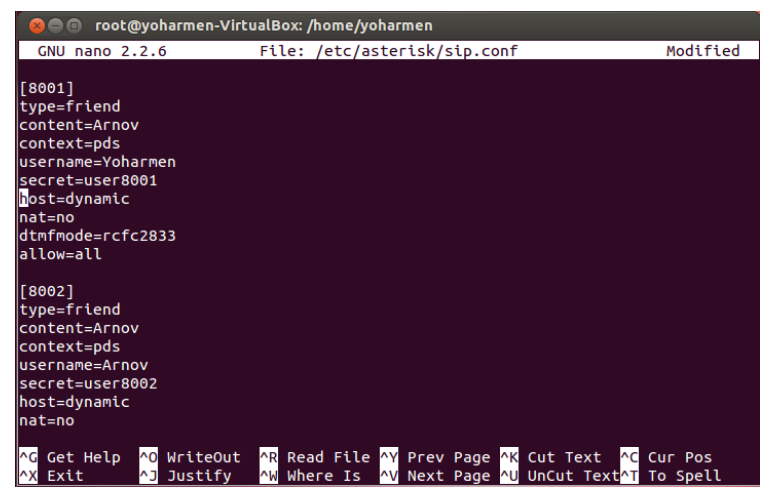

Gambar 25.Tampilan konfigurasi sip.conf

Tampilan konfigurasi extensions.conf untuk detail dari user VOIP dijelaskan pada Gambar 26.

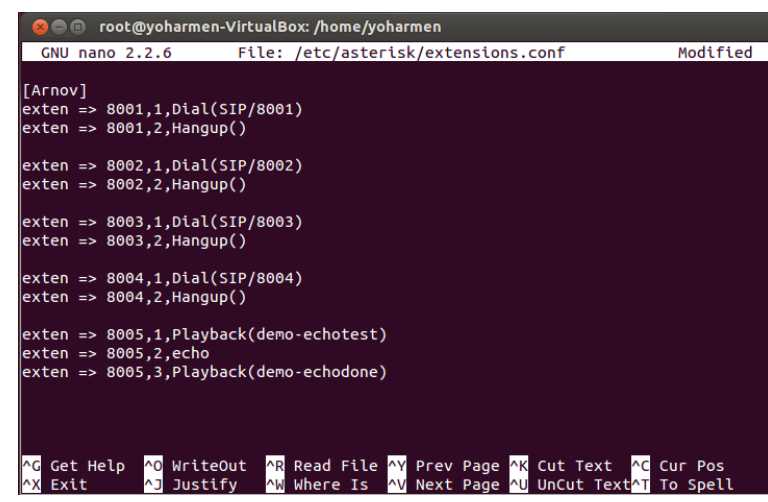

Gambar 26.Tampilan konfigurasi extensions.conf

\section{KESIMPULAN \\ Adapun kesimpulan yang didapat dari perancangan Aplikasi}


Komunikasi VOIP (arnoVoip) pada Smartphone berbasis Android adalah sebagai berikut:

1. Dengan pemanfaatan smartphone berbasis android dihasilkan aplikasi untuk komunikasi suara dan pesan melalui IP (Internet Protocol) serta DNS (Domain Name Server) dengan teknologi VOIP (Voice Over Internet Protocol).

2. Dengan Server Internal dapat meminimalisir anggaran biaya berkomunikasi bila dibandingkan dengan komunikasi telefon konvensional (telefon rumah/dialup).

3. Aplikasi arnoVoip dapat dipakai oleh banyak pengguna (multiuser).

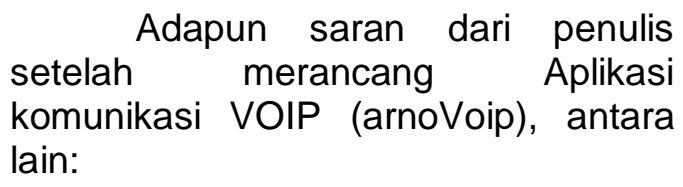
lain:

1. Diharapkan aplikasi arnoVoip ini dapat berkontribusi dan dikembangkan untuk memudahkan komunikasi suara dan pesan menjadi lebih baik.

2. Instansi dan perusahaan dapat meminimalisir pengeluaran biaya komunikasi dengan menggunakan aplikasi ini.

\section{DAFTAR PUSTAKA}

[1] Alfa Satyaputra dan Eva Maulina Aritonang. 2016. Let's Build Your Android Apps with Android Studio. Jakarta: Jasakom.

[2] Purbo, Onno W. 2007. VolP Cikal Bakal "Telkom Rakyat". Yogyakarta: Infokomputer.

[3] Safaat H, Nazruddin. 2015. Pemograman Aplikasi Mobile Smartphone dan Tablet PC Berbasis Android. Bandung: Informatika.

[4] Sugeng, Winarno. 2007. Membangun Telepon Berbasis Voip. Bandung: Informatika.
[5] Universitas Negeri Padang. 2010. Buku Panduan Penulisan Tugas Akhir/Skripsi Universitas Negeri Padang. Padang: Universitas Negeri Padang. 